(RESEARCH ARTICLE)

\title{
Comparing the attitudes and knowledge of psychiatric residents about psychotherapy before and after the psychotherapy rotation
}

\author{
Ali Nazeri astaneh, Neda Ali Beigi * and Farzad Nassirifar \\ ${ }^{1}$ Associate Professor of Psychiatry, Psychosis Research Center, University of Social Welfare and Rehabilitation Sciences, \\ Tehran, Iran. \\ ${ }^{2}$ Assistant Professor, Psychosis Research Center, University of Social Welfare and Rehabilitation Sciences, Tehran, Iran. \\ Corresponding Author. \\ ${ }^{3}$ Department of Psychiatry, University of Social Welfare \& Rehabilitation Sciences, Tehran, Iran.
}

Publication history: Received on 09 November 2020; revised on 20 November 2020; accepted on 22 November 2020

Article DOI: https://doi.org/10.30574/wjarr.2020.8.2.0417

\begin{abstract}
Introduction: The evidence show that the attitudes to any specialty can be improved as a result of a skillful and interested presentation and negative attitudes toward psychiatry can be the particular target in clinical and non-clinical courses [1]. The present study aimed to compare the attitudes and knowledge of psychiatric residents about psychotherapy before and after the psychotherapy rotation.

Methodology: The present study was a descriptive research using causal-comparative method. The population consisted of all psychiatric residents in the universities of Tehran in 2018-2019. The study was a census and all residents were asked to participate if they were willing to. From different universities of medical sciences including Iran, Shahid Beheshti, Tehran, Social Welfare and Rehabilitation Sciences, 27, 24, 25, and 41 subjects were included in the study, respectively. The total number of subjects was 117 . The researcher-made questionnaire was used for three groups of residents to assess their psychiatric attitudes and knowledge: the residents who passed the theoretical and practical psychotherapy courses, the residents who have not yet passed the psychotherapy course, and those who were passing the theoretical course. Cronbach's alpha coefficients for internal consistency of attitude and knowledge were 0.953 and 0.985 , respectively.
\end{abstract}

Findings: one-way variance analysis test was used to analyze the variables. According to the results of this test, there was a significant difference among the psychiatric residents in terms of knowledge and attitude $(\mathrm{p}<0.01)$. Moreover, regarding the means obtained for each group, it can be said that the residents who passed the theoretical and practical courses of psychotherapy had higher mean in attitude and knowledge than the other two groups; the difference was statistically significant.

Conclusion: in any educational relationship, the attitudes of educators and learners play a key role in effectiveness and success. The psychotherapy course can change the negative stereotypes about psychiatry in psychiatrists and provide an important opportunity to change their negative attitudes.

Keywords: Attitude; Knowledge; Psychiatric Residents; Psychotherapy

\footnotetext{
${ }^{*}$ Corresponding author: Neda Ali beigi

Assistant Professor, Psychosis Research Center, University of Social Welfare and Rehabilitation Sciences, Tehran, Iran. 


\section{Introduction}

Training the specialized course of psychiatry in most countries that play a key role in clinical education, including Western Europe and North America, has similar components that psychotherapy training is one of the most important and considerable parts. In Iran, the current course of psychiatry lasts for four years, which is implemented in all universities training residents under the supervision of the board based on the curriculum approved by the Ministry of Health and Medical Education. Currently, the psychotherapy training rotation comprises nine months of full time training for psychiatric residents. Most universities have succeeded to provide the infrastructure and instructors required to manage this rotation optimally, and the universities that lack such facilities have a joint program send residents to the mother universities with the desired training course for optimal education as guests [2,3].

Studies have shown that for medical students, the psychiatric therapies are of less efficiency than other specialties [4,5]. However, sufficient and strong evidence have indicated that psychiatric therapies are in general equal or better than usual therapies in other specialties [6]. Another negative attitude is that psychiatry is advancing rapidly and has no brighter future than other specialties. These attitudes can be changed during psychiatry training. The evidence shows that attitudes toward any specialty can be improved by a skillful and enthusiastic presentation, and negative attitudes toward psychiatry can be one of the special goals in clinical and non-clinical courses of psychiatry [1].

The psychotherapy rotation of psychiatry is an opportunity that forms the clinical identity of most psychiatrists, and instructors consider it as an opportunity to teach illnesses and their treatments, to strengthen professional standards, and to choose the specialized major by students $[7,8,9,10]$. The psychotherapy rotation of psychiatry can change the negative stereotypes about psychiatry in psychiatrists and provide an important opportunity to change their negative attitudes. Studies have shown that as medical students' attitudes toward psychotherapy improve, the more people will decide to study psychiatry to specialize and eventually choose psychiatry as a specialty [7].

In an Iranian study, the effect of psychiatry courses on the attitudes of fifth year medical students towards psychiatry and their willingness to choose this field as a profession was investigated. The results of this study showed that after this course, the students' attitudes toward psychiatry improved and their willingness to continue studying in this field increased [11]. Consistent with this result, Bulbana et al [12] and Barnett et al [13] indicated that after passing the psychiatric course, the students' opinions became more realistic and thus, the number of students who were willing to choose psychiatry as their future profession has increased [12,13]. Shalbafan [3] showed that training the psychiatric residents has been considerably improved in training psychotherapy training and the residents have reported the quality and quantity of training as desirable. The results of the studies by Riyahi et al [14] and Mo'men Heravi et al [15] confirmed these results.

Despite of little research on attitudes toward psychiatry, there was no research on attitudes toward psychotherapy. It seems that the psychotherapy rotation is not known for physicians, which changes the people's view after that. This difference in attitude can also justify the negative views toward psychiatry and the need for prior familiarity with psychotherapy before choosing residency. On the other hand, in any educational relationship, the attitude of educators and learners is a key point in the efficiency and effectiveness of that relationship. In the previous studies, the issue of quality of training the residents have not been the main focus. Furthermore, since psychiatric residents studying in different universities in Tehran do not receive standard and uniform training in psychotherapy, conducting such a study to compare the attitudes and knowledge of psychiatric residents about psychotherapy before and after the rotation seems necessary.

\section{Material and methods}

The present study was causal-comparative. The population consisted of all psychiatric residents studying in medical universities in Tehran in the academic years 2018-2019. The study was a census and all the residents were asked to participate in the study if they were willing to.

A total number of 117 subjects (27 subjects from Iran University of Medical Sciences, 24subjects from Shahid Beheshti University of Medical Sciences, 25 subjects from Tehran University of Medical Sciences, and 41 subjects from Social Welfare and Rehabilitation University) completely answered the questionnaire. 40 subjects had not passed the psychotherapy rotation, 37 subjects had passed it and 40 subjects were passing it.

\subsection{Tools}


The questionnaire to assess psychiatric residents' attitude and knowledge: a researcher made questionnaire was used to assess residents' attitude and knowledge. In this questionnaire, two factors of psychiatric residents' attitude and knowledge were assessed in a 5-option Likert scale. 15 experts in psychiatry were asked to evaluate the questionnaire based on the subject of research, present the required changes, and add the required items and remove the unrelated items in case of inconsistency. Finally, a questionnaire with 47 items was made. At first, to examine validity and reliability of the questionnaire, 45 residents (15 residents who had not passed the psychotherapy rotation, 15 who had passed it and 15 who were passing the rotation) were selected and completed the questionnaire.

Confirmatory factor analysis and Cronbach's alpha were used to estimate the good validity and reliability of the research tool. Cronbach's alpha coefficients for internal consistency of knowledge and attitude items were 0.953 and 0.985 , respectively. Also, the results of confirmatory factor analysis showed that factor loads of knowledge items and attitude items were in a significant range of 7.59 to 14.19 and 6.53 to 12.66 , respectively. Also, in the standard estimation of factor loads, knowledge items and attitude items were obtained as 0.63 to 0.96 and 0.60 to 0.94 , respectively. The internal consistency coefficients for knowledge was 0.953 and for attitude as 0.985 , indicating reliability of the research tool.

Structural equations analysis showed two hidden variables: 1. Knowledge and 2. Attitude. In modeling structural equations, all fit indices were in good conditions.

Table 1 Values of fit indices of the model and the results of the fit

\begin{tabular}{|l|l|l|}
\hline The model value & The optimal value & Fit index \\
\hline 2.63 & $<3.00$ & X'df \\
\hline 0.94 & $>0.90$ & GFI (goodness of fit index) \\
\hline 0.92 & $>0.90$ & $\begin{array}{l}\text { AGFI (adjusted goodness of fit } \\
\text { index) }\end{array}$ \\
\hline 0.92 & $>0.90$ & NFI (normed fit index) \\
\hline 0.92 & $>0.90$ & NNFI (non-normed fit index) \\
\hline 0.94 & $>0.90$ & IFI (Incremental Fit Index) \\
\hline 0.94 & $>0.90$ & CFI (Comparative Fit Index) \\
\hline 0.078 & $<0.08$ & $\begin{array}{l}\text { RMSEA (Root Mean Square Error } \\
\text { of Approximation) }\end{array}$ \\
\hline
\end{tabular}

\subsection{Implementation method}

All psychiatric residents in the medical universities of Iran, Shahid Beheshti, Tehran, and Social Welfare and Rehabilitation were invited to answer the researcher made questionnaire. Assuring goodness of research tools, all residents were justified about the research objective and goals and completed the questionnaire under a specific code without mentioning the name after signing the written consent forms. The psychiatric residents answered the questionnaire in a self-report form and returned it back to the researcher after two to four days as agreed.

\subsubsection{Ethical Issues}

This study was approved by the research ethics committee of University of Social Welfare and Rehabilitation Sciences, Tehran, Iran (IR.USWR.REC. 941900004). The consent forms were collected from all participants and only individuals who were willing were included in the study. It was explained to all participants that the information is due to a research project and the questionnaires are anonymous.

\subsection{Findings}

117 questionnaires were analyzed, 70 of which were completed by females and 47 by males. 42 subjects were single and 75 were married. 41 were studying in Welfare University, 24 subjects in Shahid Beheshti University, 27 subjects in Iran University, and 25 subjects in Tehran University of Medical Sciences. 
Table 2 shows the means and standard deviations of knowledge and attitude among the residents. It reports the results of three groups of residents: one group who had not passed the psychotherapy course, the residents who were passing the course, and those who had passed it.

Table 2 The means and standard deviations of knowledge and attitude scores of residents

\begin{tabular}{|c|c|c|c|c|}
\hline Variable & Group & Mean & $\begin{array}{l}\text { Standard } \\
\text { deviation }\end{array}$ & Number \\
\hline \multirow[t]{3}{*}{ Knowledge } & The residents who had not passed the psychotherapy course & 69.10 & 10.50 & 40 \\
\hline & The residents who were passing the psychotherapy course & 77.37 & 7.04 & 37 \\
\hline & $\begin{array}{l}\text { The residents who had passed the theoretical and practical } \\
\text { psychotherapy courses }\end{array}$ & 148.87 & 14.91 & 40 \\
\hline \multirow[t]{4}{*}{ Attitude } & The residents who had not passed the psychotherapy course & 17.97 & 2.42 & 40 \\
\hline & The residents who were passing the psychotherapy course & 20.81 & 2.09 & 37 \\
\hline & \multirow{2}{*}{$\begin{array}{l}\text { The residents who had passed the theoretical and practical } \\
\text { psychotherapy courses }\end{array}$} & 35.85 & 4.08 & 40 \\
\hline & & & & \\
\hline
\end{tabular}

Multi-variate variance analysis test was used to examine if the difference in observation is statistically significant. To investigate the hypotheses of variance analysis, $\mathrm{M}$ box test was used to examine the homogeneity of variance-covariance matrix of the research variables. $M$ box was 79.112, which was significant at the level of 0.05 , indicating that the condition of homogeneity of variance-covariance matrix was well observed ( $F=12.850, p>0.05)$. Levin test was used to examine the equality of variances of knowledge and attitude scores among the residents. The results indicated that the variances of knowledge and attitudes scores in the three groups were equal and could be found no significant difference (knowledge: $\mathrm{F}=4.121, \mathrm{P}>0.248$ ) (attitude: $\mathrm{F}=3.842, \mathrm{P}>0.056$ ).

Table 3 Significance test to compare the means of group scores in the variables of knowledge and attitude

\begin{tabular}{|l|l|l|l|l|l|}
\hline Test & Value & $\begin{array}{l}\text { Variance } \\
\text { analysis }\end{array}$ & $\begin{array}{l}\text { Degree of } \\
\text { item freedom }\end{array}$ & $\begin{array}{l}\text { Degree } \\
\text { error } \\
\text { freedom }\end{array}$ & $\begin{array}{l}\text { Significance } \\
\text { level }\end{array}$ \\
\hline Pillai's trace & 0.942 & 50.791 & 4 & 228 & 0.001 \\
\hline Wilks Lambda & 0.075 & 150.006 & 4 & 226 & 0.001 \\
\hline Hostelling's trace & 12.128 & 339.595 & 4 & 224 & 0.001 \\
\hline Roy's largest root & 12.109 & 690.234 & 4 & 114 & 0.001 \\
\hline
\end{tabular}

The results of Table 3 show that the group effect on linear composition of dependent variables is significant. This reveals that the two groups were significantly different at least in one dependent variable.

The results of skewness and kurtosis test to examine the normality of the distribution of scores of knowledge and attitude showed that the value of skewness observed for knowledge and attitude was in the range of $(2,-2)$. This shows that the distribution of variable had normal kurtosis.

The results of Table 4 shows that there was a difference among the psychiatric residents in terms of knowledge and attitude $(\mathrm{p}<0.01)$. Moreover, considering the means, it can be said that the residents who had passed the theoretical and practical psychotherapy courses had higher means in terms of knowledge and attitude than the other two groups. The difference was statistically significant. 
Table 4 The results of multi-variate variance analysis to compare the means of scores of the groups in attitude and knowledge

\begin{tabular}{|c|c|c|c|c|c|c|}
\hline \multicolumn{2}{|c|}{$\begin{array}{c}\text { Dependent } \\
\text { variable }\end{array}$} & $\begin{array}{c}\text { Sum of } \\
\text { squares }\end{array}$ & $\begin{array}{c}\text { Degree of } \\
\text { freedom }\end{array}$ & $\begin{array}{c}\text { Squares } \\
\text { mean }\end{array}$ & $\begin{array}{c}\text { Variance } \\
\text { analysis }\end{array}$ & $\begin{array}{c}\text { Significance } \\
\text { level }\end{array}$ \\
\hline \multirow{2}{*}{ Group } & Knowledge & 148593.955 & 2 & 74296.977 & 573.657 & 0.001 \\
\cline { 2 - 7 } & Attitude & 7332.215 & 2 & 3666.108 & 402.733 & 0.001 \\
\hline \multirow{2}{*}{ Error } & Knowledge & 14764.678 & 114 & 129.515 & & \\
\cline { 2 - 7 } & Attitude & 1037.751 & 114 & 9.103 & & \\
\hline \multirow{2}{*}{ Total } & Knowledge & 1301972 & 117 & & & \\
\cline { 2 - 7 } & Attitude & 81395 & 117 & & & \\
\hline
\end{tabular}

\section{Results and discussion}

According to the results, the means and standard deviations of knowledge in the three groups of residents who had not passed the psychotherapy course, the residents who were passing the theoretical course of psychotherapy, and those who had passed the theoretical and practical psychotherapy courses were 69.10 (10.50), 77.37 (7.04), 148.8 (14.91), respectively. Also, the means and standard deviation of attitude in the three groups were 17.97 (2.42), 20.81 (2.09), 35.85 (4.08), respectively. Multivariate variance analysis test showed that there was a significant difference between involvement levels of psychotherapy of psychiatric residents in terms of knowledge and attitude of psychotherapy. The residents who had passed the theoretical and practical courses of psychotherapy had higher mean in terms of knowledge and attitude; the difference was significant. The results are in line with the results found by Amini et al [5 ], Shalbafan [3], Riyahi et al [14], Alipour [16], Mo'men Heravi et al [15 ], Moghani et al [17], Bulbana, Pilhis, Cool, and Balon [12 ], Barnett et al [13 ], and Sadr et al [2].

Shalbafan [3] showed that training the psychiatric residents has caused considerable improvement in training psychotherapy, and the residents reported the quality and quantity of training as desirable. Ryahi et al [14] showed that interest in choosing the field of psychiatry, the attitude toward psychiatry, and attitude toward each of components of the educational course improved after passing the psychiatric internship. Mo'men Heravi et al [15] indicated the efficiency of the course in increasing the learners' knowledge and awareness toward the educational content. Barnett et al [13] showed that the psychotherapists who had positive attitudes toward teaching methods had positive attitudes toward the educational sessions and content and participated in it actively. Furthermore, Bulbana, Pilhis, Cool, and Balon [12] showed that the students' attitudes became more realistic after passing the psychiatric course; thus, the number of students who want to choose psychiatry as their future profession increases.

The course of psychiatric psychotherapy can change the negative stereotypes about psychiatry in psychiatrists and provides an important opportunity to change the negative attitudes. Some studies have shown that as medical students' attitudes toward psychotherapy improve, the more people will decide to study psychiatry to specialize and eventually choose psychiatry as a profession [7]. Negative attitudes are sometimes the result of insufficient and incorrect information. For example, students consider the psychiatric therapies less effective than other specialties. While there is strong and sufficient evidence that psychiatric therapies are in general equal or beyond usual therapies in other specialties [6]. Another negative attitude is that psychiatry is advancing rapidly and has no brighter future than other specialties. These attitudes can be changed during psychiatry training. The evidence shows that attitudes toward any specialty can be improved by a skillful and enthusiastic presentation, and negative attitudes toward psychiatry can be one of the special goals in clinical and non-clinical courses of psychiatry [1].

Generally speaking, it can be concluded that the attitudes and knowledge of the residents about psychotherapy are greatly influenced by the passage of time, and this change in attitude may have a direct effect on the attitude towards the field of study. The tendency to start psychotherapy from the lower years of the residency has recently increased and unlike the past, many universities provide psychotherapy training from the first and second years of residency, which can have a positive effect on attitudes toward the field of study and the tendency to use psychotherapy along with medication for patients, as the previous research has confirmed this point.

Self-reporting of the research tools, lack of previous standard questionnaire, difficulty in classifying residents in three groups, lack of more consistent and inconsistent research in line with the present study and lack of cooperation of some 
residents can be mentioned as some of limitations of this study. This is the first study investigating the effect of psychotherapy course on knowledge and attitude of the residents. It is suggested to study larger sample size with different dimensions of attitude. Also, in this study, the quality of psychotherapy is not mentioned and all universities are examined together, while the type of education and educator will have a significant impact on creating new attitudes and thus, it is suggested to consider this issue in further studies in the future.

\section{Conclusion}

The residents who had passed the theoretical and practical psychotherapy courses had higher means in terms of knowledge and attitude than the other two groups $(\mathrm{p}<0.01)$. The course of psychiatric psychotherapy can change the negative stereotypes about psychiatry in psychiatrists and provides an important opportunity to change the negative attitudes. The attitudes and knowledge of the residents about psychotherapy are greatly influenced by the passage of time.

\section{Compliance with ethical standards}

\section{Acknowledgments}

We thereby appreciate all the residents of universities of medical sciences in Tehran, who helped us in this research.

\section{Disclosure of conflict of interest}

There is no conflict of interest in this research.

\section{Ethical Approval}

This study was approved by the research ethics committee of University of Social Welfare and Rehabilitation Sciences, Tehran, Iran (IR.USWR.REC. 941900004).

\section{References}

[1] Richards, M., Hori, H., Sartorius, N., \& Kunugi, H. Cross-cultural comparisons of attitudes toward schizophrenia amongst the general population and physicians: a series of web-based surveys in Japan and the United States. Psychiatry research, 2014; 215(2):300-307.

[2] Sadr S.S., Nayerifard, R. Samimi Ardestani, S.M. Namjoo, M. Factors Affecting the Choice of Psychiatry as a Specialty in Psychiatry Residents in Iran. Iran J Psychiatry; 2016; 11.3:185-190.

[3] Shalbafan, Muhammedreza. The Place of Psychotherapy in Training Program of Psychiatric Residents. $4^{\text {th }}$ Conference of Behavioral-cognitive Psychotherapy in Iran University of Medical Sciences. 2016; 4(1):56-57.

[4] Strauss, B., Spangenberg, L., Brahler, E., \& Bormann, B. Attitudes towards (psychotherapy) groups: Results of a survey in a representative sample. International journal of group psychotherapy, 2015; 65(3):410-430.

[5] Amini H, Nejatisafa AA, Shoar S, Kaviani H, Samimi-Ardestani M, Shabani A, et al. Iranian medical students' perception of psychiatry: before and after a psychiatry clerkship. Iranian Journal of Psychiatry 2013; 8:37-43.

[6] Timpson, D., Priest, H., \& Clark-Carter, D. Adolescents who self-harm: Professional staff knowledge, attitudes and training needs. Journal of Adolescence, 2012; 35(5):1307-1314.

[7] Bhugra, D., Sartorius, N., Fiorillo, A., Evans-Lacko, S., Ventriglio, A., Hermans, M. H. M., ... \& Bennemar, M. R. EPA guidance on how to improve the image of psychiatry and of the psychiatrist. European Psychiatry, 2015; 30(3):423-430.

[8] Abbas, S., Ihle, P., Adler, J. B., Engel, S., Günster, C., Holtmann, M., \& Schubert, I. Predictors of non-drug psychiatric/psychotherapeutic treatment in children and adolescents with mental or behavioural disorders. European child \& adolescent psychiatry, 2017; 26(4):433-444.

[9] Taylor, J., Stubbs, B., Hewitt, C., Ajjan, R. A., Alderson, S. L., Gilbody, S., ... \& Kellar, I. The effectiveness of pharmacological and non-pharmacological interventions for improving glycemic control in adults with severe mental illness: a systematic review and meta-analysis. Plops one, 2017; 12(1): e0168549. 
[10] Dahl, J., Ormstad, H., Aass, H. C. D., Sandvik, L., Malt, U. F., \& Andreassen, O. A. Recovery from major depressive disorder episode after non-pharmacological treatment is associated with normalized cytokine levels. Acta Psychiatrica Scandinavica, 2016; 134(1):40-47.

[11] Firuzabadi, Ali; Bahrebardar, Muhammed Ja'far; Kiyanpour, Mohsen; Ommizade, Seyed Javad. Evaluating and Comparing the Medical Students' Attitude Toward Psychiatric Patients (Shiraz-2005). The Journal of Semnan University of Medical Sciences. 2006; 2(8):49-52.

[12] Bulbena, A., Pailhez, G., Coll, J., \& Balon, R. Changes in the attitudes towards psychiatry among Spanish medical students during training in psychiatry. The European journal of psychiatry, 2005; 19(2):79-87.

[13] Barnett, M., Brookman-Frazee, L., Regan, J., Saifan, D., Stadnick, N., \& Lau, A. How Intervention and Implementation Characteristics Relate to Community Therapists' Attitudes Toward Evidence-Based Practices: A Mixed Methods Study. Administration and Policy in Mental Health and Mental Health Services Research, 2017; $1-14$.

[14] Riyahi, Forugh; Izadi Mazidi, Sekine; Khaje Din, Nilufar; Salehi Veisi, Muhammed. Studying the Effectiveness of Psychiatric Internship Course on Medical Students' Attitude toward Psychiatry. Bi-monthly Journal of Jundi Shapoor, 2013; 4(3):235-244.

[15] Mo'men Heravi, Mansoore; Ahmadvand, Afshin; Sepehrmanesh, Zahra; Saei, Rezvan; Gharedaghi, Zahra. Formulating and Implementing the Curriculum of Training Mental Rehabilitation based on Society for Psychiatric Residents. Shahid Saduqi University of Medical Sciences and Health Services in Yazd. 2014; 9(13):523-524.

[16] Alipour, Yeganeh. Studying the Attitude of Residents of Different Groups of Clinical Training of Tabriz University of Medical Sciences toward the Teaching Method of Clinical Professors. Shahid Saduqi University of Medical Sciences and Health Services in Yazd (Special Issue of 15th Conference of Medical Education), 2014; 9(13):9-11.

[17] Moghani, Alireza; Khalili, Ro'ya; Dehghani, Muhammedreza; Nouruzi, Mahsa; Varzande, Zahra. Clinical Residents, Hospital Teachers, the Need for Training and Empowering the Skills of teaching-learning. Interdisciplinary Journal of Figurative Learning in Medical Sciences. 2013; 4(4):50-55. 